\title{
LA REPRESENTACIÓN DEL PODER EN LOS VIDEOJUEGOS SOBRE LA EDAD MEDIA EN LOS AÑOS 80
}

THE POWER'S REPRESENTATION IN THE VIDEOGAMES ABOUT MIDDLE AGES IN THE 1980'S

\author{
Brenda Rodríguez Seoane * \\ brendars92@gmail.com
}

RESUMEN: La visión de la Edad Media en la actualidad se crea y expande por la cultura popular audiovisual basada en el cine y los videojuegos. Dentro de la diversa temática de la que éstos pueden tratar, el poder y las relaciones sociales es una de las que más llama la atención. Por ello, en este artículo trataremos de explicar brevemente los elementos y relaciones de poder que podemos hallar en una serie de videojuegos creados en la década de los ochenta del siglo XX.

Palabras ClaVE: Neomedievalismo, Poder, Relaciones, Videojuegos, Edad Media.

ABSTRACT: The vision of Middle Ages today is created and expanded by the popular audiovisual culture based on cinema and video games. Within the diverse subject matter they can deal with, power and social relations are one of the most striking subjects. Therefore, in this article we will try to explain briefly the elements and power relationes that we can find in some video games born in the eighties of the twentieth century.

KEYWORDS: Neomedievalism, Power, Relationes, Video games, Middle Ages.

\section{Introducción}

En la actualidad, la industria de los videojuegos es una de las formas de entretenimiento con mayor desarrollo. Gracias a su éxito, consiguen llegar a un público heterogéneo $y$, por ello, son diversas las temáticas de las que tratan ya que existen, entre otros, géneros fantásticos, futuristas e históricos. Entre estos últimos, destaca la Edad Media como una época recurrente en la que se entrelazan elementos actuales con otros propiamente medievales. La consecuencia es la aparición de una nueva concepción moderna de lo que se considera medieval, conocido como neomedievalismo. A partir de esta representación cultural de dicho período aparece una visión propia creada en cada título desarrollado.

Por ello, este artículo se centra en la visión y representación del período medieval en tres videojuegos de los años ochenta elegidos por su importancia: Nonamed, Defender of the Crown y Iron Lord. A partir de su análisis, este trabajo se centrará en la representación del poder en cada uno de ellos, explicado en dos vertientes. Por una parte, los elementos que representan el poder como son la figura del rey y de la nobleza así como el espacio en que el poder se fragua o los peligros de su pérdida. Por otra, se enumerarán brevemente los

\footnotetext{
* Doctoranda en Historia Medieval de la Universidad de Santiago de Compostela. Se especializa en la historia de los videojuegos españoles sobre la Edad Media.
} 
conceptos de representación, tanto los que aparecen en el argumento de los juegos, como las relaciones sociales entre el Rey y los caballeros o la concepción del enemigo.

\section{El Neomedievalismo}

La Edad Media es un período histórico que ha suscitado un gran interés a lo largo de los siglos posteriores. Si bien sufrió una consideración negativa durante el Renacimiento y la Ilustración, a partir del siglo XVIII vuelve a ser relevante para los intelectuales de la época. Autores como Walter Scott, Horace Walpole o Wordsworth centran sus novelas en una visión romántica de dicho período como forma de evasión de la forma de vida moderna. ${ }^{1}$ De esta forma es como surge una concepción de la época medieval basada en ideales románticos sobre sus habitantes, su espiritualidad y sus episodios históricos. Esta concepción se conoce como neomedievalismo, término acuñado por Umberto Eco en su ensayo Dreaming the Middle Ages en $1986 .^{2}$

A partir de dicha obra, han sido varios los autores que se han centrado en la explicación de la unión entre esos elementos fantásticos formados en la cultura popular actual y el período medieval. ${ }^{3}$ El término en sí ha sido producto de varios debates en la comunidad historiográfica debido a su complejidad y las diferentes posturas sobre el tratamiento de la historia. ${ }^{4}$ Los rasgos definitorios de dicha concepción moderna sobre la Edad Media se repiten en sus representaciones basadas en una concepción occidental y europea de dicho periodo. Elementos como los castillos, los valientes caballeros cristianos o las princesas se utilizan de forma reiterativa para fomentar una visión homogénea de un período de tiempo que se prolonga diez siglos.

\footnotetext{
${ }^{1}$ A finales del siglo XVIII comenzó una corriente intelectual inglesa de oposición al Racionalismo y a la vida urbana. Así, se consideró la Edad Media como una época sobrenatural (SELLING, 2004, p.213).

2 "Thus we are at present witnessing, both in Europe and America, a period of renewed interest in the Middle Ages, with a curious oscillation between fantastic neomedievalism and responsable philological examination" (ECO, 1986, p.62).

3 "Medieval concepts and values are purposely rewritten as a consious vision of an alternative universo (a fantasy of the medieval that is created with forethought). Contemporary values (feminis, gay rights, modern technological warfare tactics, democracy, capitalism...) dominate and rewrite the traditional perceptions of theEuropea Middle Ages". Disponible en: <http://medievalelectronicmultimedia.org/?page_id=39>. Consulta: 10 sept. 2019).

4"Neomedievalism finds a way of clinging to the past by rejecting the history, the alterity, the time and space that separated it from its desired object and bringing i tinto the present but (...) be a desire for history alongside the uncomfortable suspicion that there is no such thing" (KAUFMAN, 2010, p. 3).
} 
Como consecuencia, la cultura actual nacida de este tratamiento de la historia se basa en un conjunto de ideas fragmentadas y reelaboradas que no guardan relación con el período descrito. Esta visión anacrónica de la Edad Media provoca que la sociedad actual conozca una realidad distorsionada, en la que se entrelazan hechos y personalidades históricas ajenas a su época con elementos fantásticos. Así, suelen aparecer caracteres de la fantasía actual como elfos, orcos o dragones; ambientados en un mundo medieval. Se suceden los títulos que tratan esta temática, desde las obras de Tolkien El Hobbit o El Señor de los Anillos, hasta la serie de éxito internacional Juego de Tronos, basada en la saga de George R.R. Martin. Los videojuegos no son ajenos al neomedievalismo y cada vez se suceden más obras que se basan en ello, con títulos tan conocidos como Zelda, Assassins Creed o The Witcher.

\section{Elección de videojuegos}

Basándonos en el estudio de la visión de la Edad Media en la actualidad, hemos escogido para este artículo tres videojuegos, con los cuales expondremos brevemente la representación del poder descrito en ellos. Dicha elección se basa en criterios de cantidad y calidad, ya que sería imposible llevar a cabo una síntesis de todos los títulos que existen sobre esta temática.

La primera característica en común de estos tres títulos es que se trata de videojuegos de la década de los años ochenta del siglo XX. La elección es clara, es la década en la que se comienza a fraguar la industria de los videojuegos tanto en Europa como en América, siendo un mercado con una gran expansión. En estos momentos comienza una verdadera explosión de venta de ordenadores personales $y$, junto a ella, comienzan a proliferar formas de entretenimiento para un uso personal. Así, en Reino Unido se fabrican los ordenadores de la marca Spectrum ${ }^{5}$ y gracias a su precio razonable, comienzan a expandirse rápidamente, llegando a España en poco tiempo. A la par, aparecen más marcas de ordenadores personales como el Amstrad o el Commodore, que fomentan una diversificación de títulos y temáticas a gran escala.

De la mano de esta explicación, viene el siguiente criterio de elección, ya que todos estos títulos se publican en algún momento en España, que es el ámbito de nuestro estudio. En comparación con países como Reino Unido o Francia, el desarrollo de esta industria en

\footnotetext{
${ }^{5}$ El ingeniero británico Clive Sinclair creó el ZX80 en 1980, el ZX81 en 1981 y, posteriormente, el ZX Spectrum en 1982 (ESTEVE GUTIÉRREZ, 2012).
} 
nuestro país fue relativamente tardío. Las noticias de diversos juegos y mejoras llegaba en un primer momento desde revistas inglesas o francesas, ${ }^{6}$ aunque desde un primer momento hubo un afán por piratear los juegos que llegaban y programar algunas mejoras personalizadas.

Por tanto, los tres títulos escogidos son Iron Lord, Defender of the Crown y Nonamed. Los tres se caracterización no sólo por tratar temática medieval, sino por ser un hito y novedad en la industria de la época.

Defender of the Crown fue lanzado para Commodore Amiga en 1986 aunque después se editó en varias plataformas. Marcó un antes y un después ya que fue el primer título de la compañía Cinemaware. ${ }^{7}$ Este título fue un éxito en la época ya que tenía unos gráficos nunca vistos hasta la fecha, convirtiéndose en uno de los juegos más vendidos de los años ochenta.

Iron Lord es un videojuego con una larga historia ya que en un primer momento fue lanzado por la compañía francesa Ubi Soft para Atari ST en 1989 y, posteriormente, para los ordenadores Commodore, Amstrad y Spectrum. Sufrió una serie de cambios en sus gráficos debido a la diferencia de capacidad de los ordenadores de la época. Pero sobre todo es recordado por ser uno de los primeros juegos que está formado por minijuegos dentro del mismo. Así, tiene una primera parte de aventura narrada en la que el personaje interactúa con el pueblo para así conseguir aliados. En la segunda parte, es un juego de estrategia en el que dos ejércitos deben enfrentarse. En la última parte, es un arcade en el que personaje debe superar una serie de obstáculos.

\footnotetext{
${ }^{6}$ En España tuvieron auge tanto MicroHobby como Micromania. La primera publicación de MicroHobby fue del 5 al 11 de noviembre de 1984 (https://archive.org/details/microhobby-magazine-001.pdf/page/n1) mientras que Micromania apareció en julio $\quad$ de 1985 (https://archive.org/details/MicromaniaPrimerEpocaspanishlssue01/page/n9).

${ }^{7}$ Esta compañía desde su nacimiento se dedicó a la creación de videojuegos basados en películas.

"Cinemaware is certainly one of the most celebrated of all publishers for the Amiga. Can you tell us about the early days of Cinemaware and the state of the industry when Defender of the Crown was being developed? BJ: The industry was still in its infancy back then and games looked lousy. The graphics weren't very good. Most games were designed and didn't really have a strong mass market sensibility (...)

I also decided that movies would be a great and creative motif for doing games - people like movies, right? It gave us virtually an inexhaustible supply of ideas. I was Smart enough and cynical enough to realice that all we had to do was reach the level of copycat, and we'd be considered a breakthrough.

(...) I didn't design the game, but I knew pretty much what I wanted to do with it. Essentially, I took the game Risk - I loved the board game when I was a kid, and I liked the idea of conquering territories. We replaced the dice rolling in Risk with your success and failure at certain action sequences in the game."

(Interview: Bob Jacob on the Cinemaware. Disponible en: $<$ https://www.gamasutra.com/view/news/117527/Interview Bob Jacob On The Cinemaware Era.php. Consulta: 07 sept. 2019).
} 
Por último, Nonamed es el único de los tres títulos que fue creado por una compañía española, Dinamic, para Spectrum en 1987. Está década en España fue acuñada posteriormente como la Edad de Oro del Software Español y tuvo vigencia hasta el año $1992 .{ }^{8}$ Dinamic fue creada por en 1984 por los hermanos Ruiz, basándose para el nombre en las grandes empresas inglesas del momento como Ultimate, Ocean e Imagine (ESTEVE GURIÉRREZ, 2012, posición 1237).

\section{La representación del poder}

La sociedad en la que vivimos está basada en la cultura de lo visual y así lo demuestran la gran cantidad de consumo de cine y series en todo el mundo. Debido a la globalización y al desarrollo tecnológico, el ser humano vive en una completa conexión diaria con otras culturas y partes del mundo. Pero la masificación de información hace que en muchas ocasiones se pasen por alto algunos prejuicios y visiones de una realidad alternativa. La consecuencia inmediata es la creación colectiva de una serie de elementos que caracterizan a un pueblo, a un personaje o incluso a un período histórico. Los videojuegos son una de las vías de entretenimiento audiovisual que causan esta percepción $y$, por tanto, es importante estudiarlos para conocer esa visión actual.

Este artículo trata de la visión del poder en la Edad Media en los videojuegos y, por tanto, estudiaremos en este apartado todos esos elementos que representan dicho control. No sólo hablaremos brevemente de los personajes que ostentan el poder en los videojuegos medievales, sino también de los lugares que simbolizan dicho dominio, de los peligros a los que se enfrentan y, por supuesto de todas las relaciones que los envuelven.

\subsection{Los elementos de representación}

Nos referiremos en este apartado a todos aquellos elementos que fomentan la representación del poder político medieval en los videojuegos. En gran cantidad de videojuegos de dicha temática, el poder se basa en las relaciones sociales que mantienen los monarcas con sus súbditos y la nobleza con el pueblo llano. Tanto el rey como dichos nobles suelen portar objetos como armas y vestimentas que los hacen fácilmente reconocibles para

\footnotetext{
8 "una década brillante en la producción y desarrollo de videojuegos en nuestro país (...) jugó un papel preeminente en el desarrollo de videojuegos para máquinas de 8 bits en Europa" (ESTEVE GUTIÉRREZ, 2012, posición 117-154).
} 
los jugadores. Además, en la visión actual hay una serie de símbolos específicos como los castillos que nos sitúan en aquella época.

\section{Rey}

Cuando hablamos de la sociedad medieval el Rey, así como la Iglesia, es la representación del poder de la época, tanto en el plano social como político e incluso en muchas ocasiones, espiritual. Teniendo en cuenta que todos los títulos escogidos se basan en la visión de la Edad Media proyectada en películas de los años cincuenta y posteriores, vemos que la idea de monarca se repite. Los elementos de su figura son siempre una serie de adjetivos tanto positivos como en algunos casos, negativos. También siempre se repite como eje central en base al cual gira todo el desarrollo posterior, siendo un personaje de gran calado en prácticamente todas las películas de dicha temática. Los videojuegos no son ajenos a esta utilización como excusa del desarrollo de su argumento $y$, por tanto, describiremos brevemente qué es lo que se nos describe del soberano en cada uno de ellos.

Una de las características más importantes es la figura del rey como valedor de su pueblo, la cual aparece en los tres videojuegos. Aunque no se muestra al monarca de forma física, sí que las introducciones de todos ellos nos dan una serie de pistas en torno a su carácter como figura de poder. La primera de ellas es que es una persona que encarna la justicia, a la cual hay que rendirle veneración ya que es el protector del reino. Son adjetivos positivos que se repiten en los libretos y portadas de todos los títulos para expresar que el reino ha vivido en paz durante muchos años gracias a su mandato, como se nos dice en Nonamed. ${ }^{9}$ Todos estos juegos están centrados en territorios en los que existía una concepción teocrática del poder (la Baja Sajonia medieval, la Francia de las Cruzadas y la Inglaterra del siglo XII) ${ }^{10}$ de la que hablaremos en los posteriores puntos de este artículo.

Pero también nos encontramos con la caracterización negativa del mismo, es decir, un tirano que no cumple con su cometido como protector y valedor de sus súbditos. Por ello, debe ser destronado para conseguir que vuelva a reinar la paz en el territorio. Iron Lord es uno de los pocos títulos que nos habla sobre ese tipo de personaje y representa la contraposición

\footnotetext{
9 “En un valle olvidado de la Baja Sajonia existía un pueblo de guerreros y campesinos que rendía pleitesía a su anciano y venerable monarca, el rey ABDUL HONEICKAM GARGOY". (Nonamed", World of Spectrum, Disponible en: <http://www.worldofspectrum.org/pub/sinclair/games-info/n/Nonamed.txt>. Consulta: 01 ago. 2019).

10 "A partir de la segunda mitad del siglo VIII la anexión de dicha fórmula al título real se convirtió en un hecho normal, observable en los reinos occidentales" (ULLMANN, 1971, p.122).
} 
entre el buen y el mal gobernante. Mientras que el rey anterior era el garante de la paz; el terror y la injusticia han aparecido cuando el hermano del rey lo asesina para conseguir el trono. Así, su asesinato abre el comienzo de una venganza y una lucha entre lo que separa a un buen monarca de un mal rey. El protagonista, quien encarna los ideales de buen caballero cristiano, es el único heredero posible que puede traer de nuevo la paz al reino. ${ }^{11}$

El asesinato del monarca Ricardo I y el robo de la corona en Defender of the Crown marcan una reacción en el pueblo y es el inicio de la acción del juego, ya que el pueblo sajón se encuentra sin ningún referente político en ese momento. En un momento de crisis como era este conflicto entre pueblos, el rey es asesinado después de volver de la Cruzada, descripción interesante ya que refleja que su figura era el referente de la lucha contra el infiel. ${ }^{12}$

\section{Nobleza}

La representación de la nobleza es un recurso recurrente cuando se ambientan los videojuegos en el período medieval. Dentro de este grupo social, las figuras más y mejor representadas son los caballeros, caracterizados por una serie de elementos que se repiten a lo largo de las películas, series y videojuegos. Esta caracterización recurrente crea que se identifiquen una serie de adjetivos y descripciones a la figura del noble caballero.

El primero, es el caballero y príncipe destronado Iron Lord, quien debe recuperar el trono y devolver la estabilidad a su reino. Leyendo el libreto se nos dice que era un caballero cruzado que estuvo en Tierra Santa y tardó cinco años en volver a su reino en Francia. Este argumento aparece sustentado tanto por la portada del juego como por la pantalla de carga, en la que se nos representan una serie de escenas.

\footnotetext{
11 "Terror. Repression. Injustice. That's what awaits you as you return to the town you call your home (...) Your father The King, has been overthrown by your ruthless uncle, terror and oppression now rule this once serene Kingdom". (Iron Lord, World of Spectrum. Disponible en: <http://www.worldofspectrum.org/pub/sinclair/games-inlays/i/IronLord.jpg>. Consulta: 18 ago. 2019).

12 "The rough plot to Defender is that the Normans now occupy most of the south of Britain, with the Saxons in the north. But the Saxon King has been assassinated, and with no heir to the throne the Saxon kingdom is in disarray" (PATTERSON, 1987, p. 32-33).
} 


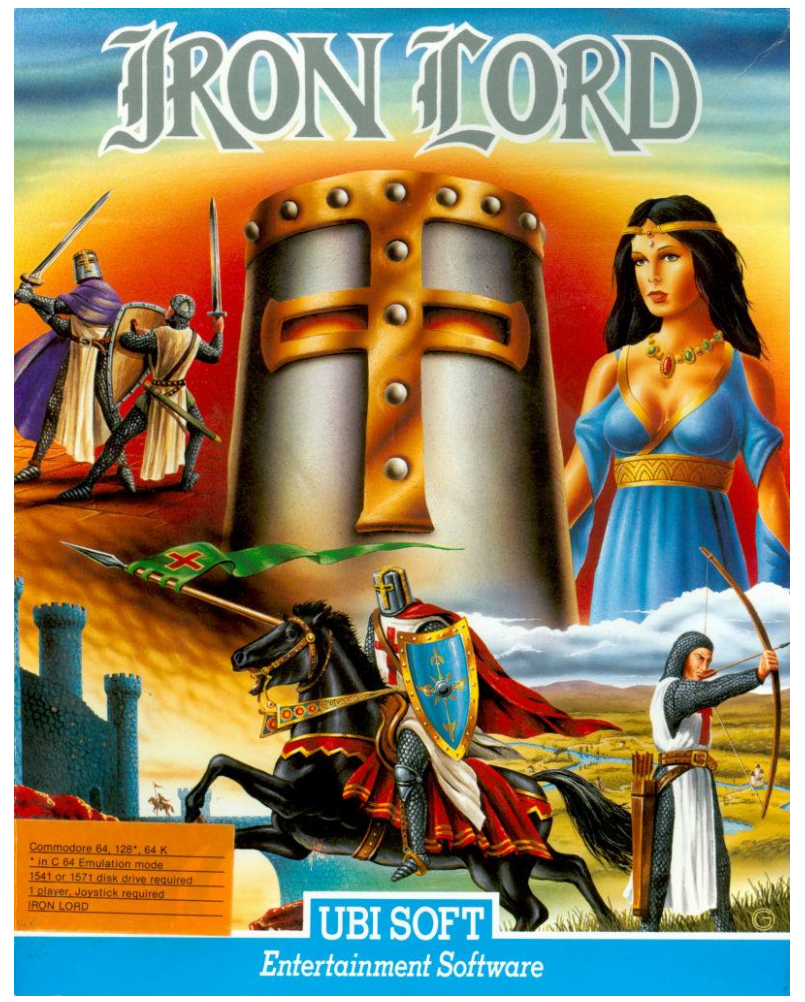

Portada videojuego Iron Lord para Commodore. Fuente: Mobygames, (Disponible en:

https://www.mobygames.com/game/c64/iron-lord/cover-art/gameCoverld,157831/>. Consulta: 5 sept. 2019)

En ellas podemos observar a un caballero templario franco, ya que viste una cota de malla entera y una túnica blanca con una cruz roja ${ }^{13}$. Además, va ataviado con un casco que le protege completamente la cabeza salvo por la visera para los ojos, lo que le permite ver de forma dificultosa a su enemigo. Debido a su función defensiva del pueblo cristiano en estos lugares de conflicto, los templarios debían ser diestros en la lucha, como podemos observar en las diversas escenas que se nos muestran. En la primera escena de la portada, podemos observar cómo el caballero lucha cuerpo a cuerpo con un enemigo, valiéndose solamente de su espada mientras que su contrincante necesita el escudo para protegerse de los golpes asestados.

${ }^{13}$ La Orden del Temple vestían de blanco ya que simbolizaba la castidad y la salud. (PAGAROLAS SABATÉ, 1996, p. 31-56) 


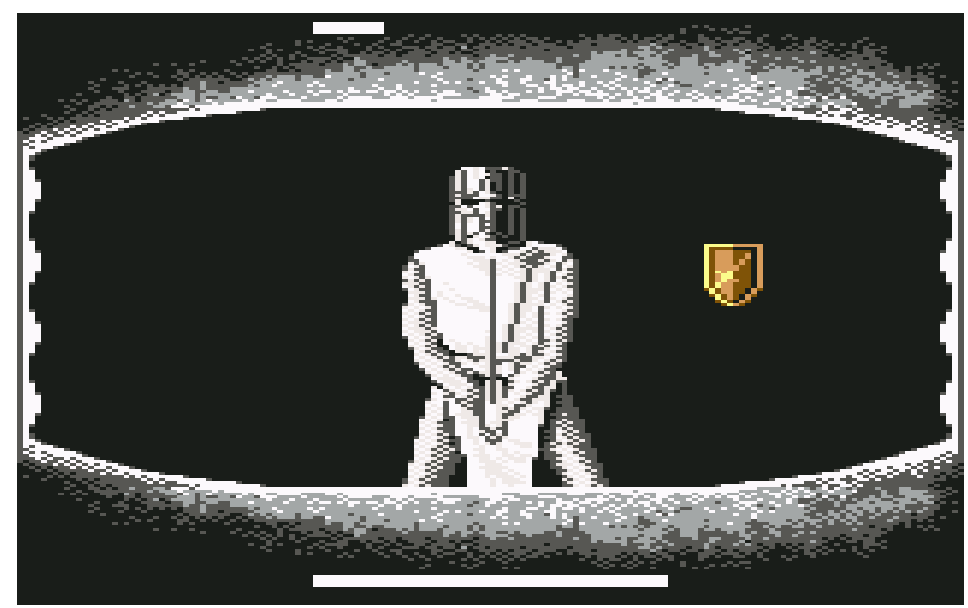

Caracterización de un caballero contra el cual se debe enfrentar el protagonista en Iron Lord en su versión para

Commodore 64. Fuente: Mobygames, (Disponible en: <https://www.mobygames.com/game/c64/ironlord/screenshots/gameShotld,129633/>. Consulta: 06 sept. 2019)

También se nos muestra que es diestro en el arco y en la lanza, siendo los tres tipos de combate característicos de esta época y fomentados en época de paz por los torneos de arco y justas. Es bastante común la representación del caballero no sólo como guerrero sino también como participante en este tipo de actividades de ocio, imprescindibles en la época no sólo como entrenamiento para los conflictos bélicos sino para la socialización. En dichos torneos asistían las clases populares, pero también los nobles, que eran los que combatían sólo esta clase social tenía el dinero suficiente para pagar un caballo, una armadura y un arma, de ahí el nombre de caballero- y forjaban relaciones sociales. En el juego el protagonista debe participar y ganar en un torneo de tiro con arco en la aldea de Chatenay Malabry. Debe llevar la copa conseguida como premio al herbolario para que éste le preste su ayuda y así conseguir un ejército, es decir, necesita renombre y fama para poder conseguir adeptos (REDRUP, 1992, p.135-138).

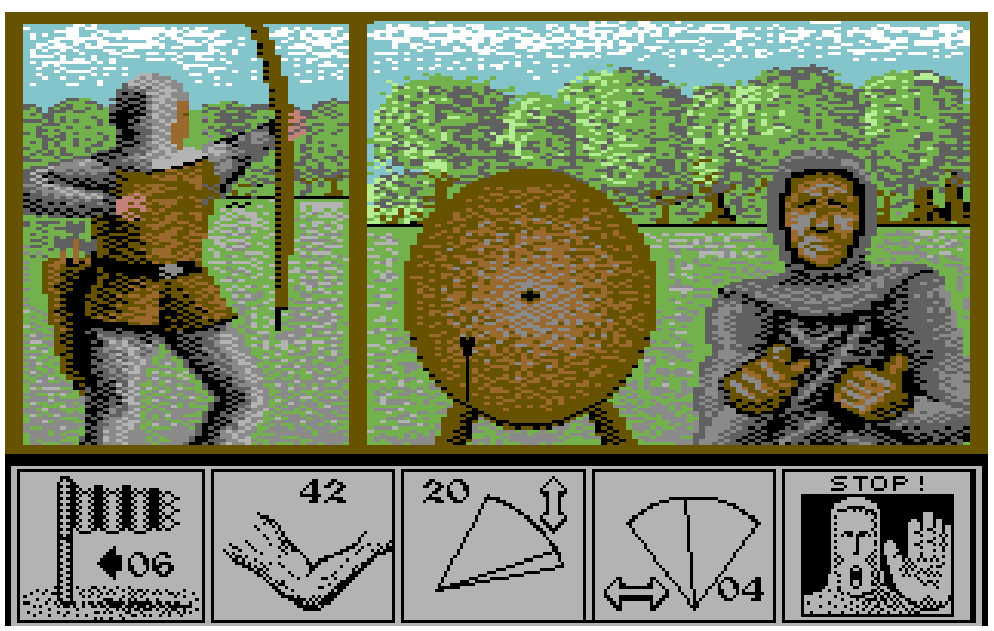

Escena de tiro con arco en la versión para Commodore 64. Fuente: Mobygames (Disponible en: <https://www.mobygames.com/game/c64/iron-lord/screenshots/gameShotld,907892/>. Consulta: 04 sept. 2019). 
Si en Iron Lord nos aparecía representado un torneo de tiro con arco, en Defender of the Crown se nos muestra una justa. Cualquier barón puede decidir celebrar una justa para así ganar fama o territorios si resulta ganador. Pero, si alguno de los contrincantes realiza una maniobra prohibida, pierde su territorio, el oro y reduce su liderazgo y fama.

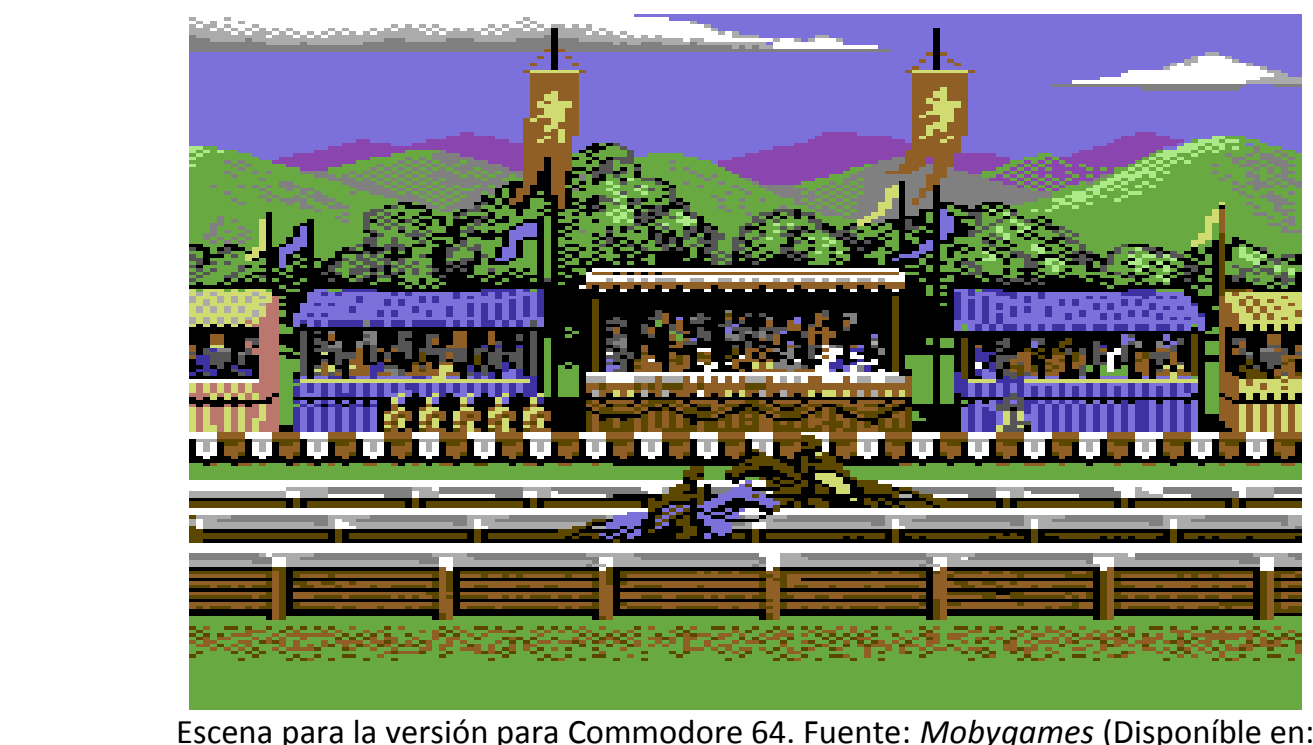

<https://www.mobygames.com/game/c64/defender-of-the-crown/screenshots/gameShotld,263982/>.

Consulta: 06 sept. 2019).

Este juego, que se basa en la novela Ivanhoe de Walter Scott y su película homónima, así como en las películas de las leyendas relativas a Robin Hood, enlaza la Inglaterra del siglo XII con estos personajes legendarios ${ }^{14}$ encuadrados en el conflicto sajón-normando. Cuando comienza el juego, se debe escoger el protagonista entre cuatro barones sajones, los cuales tienen una serie de características físicas y psíquicas que condicionan el juego. Sus nombres son Wilfred de Ivanhoe, protagonista de la novela homónima; Cedric de Rotherwood, en la novela padre de Ivanhoe; Geoffrey Longsword y Wolfric el Salvaje. El objetivo es conseguir controlar diversas tierras y castillos par así derrotar a los normandos y sajones y ser rey. Para ello, debemos escoger el mejor preparado en funciones tales como el liderazgo, la pericia en las justas y el combate con espada. Por tanto, vemos cómo estas tres características son consideradas capitales en cuanto a la descripción de todos estos caballeros. Con mayor o menor acierto, esta visión enmarca los ideales que fueron utilizados en la representación del caballero noble durante muchos años en la cultura actual.

\footnotetext{
${ }^{14}$ Interview with Jim Sachs, CU Amiga Magazine, no47, p.44-45.
} 


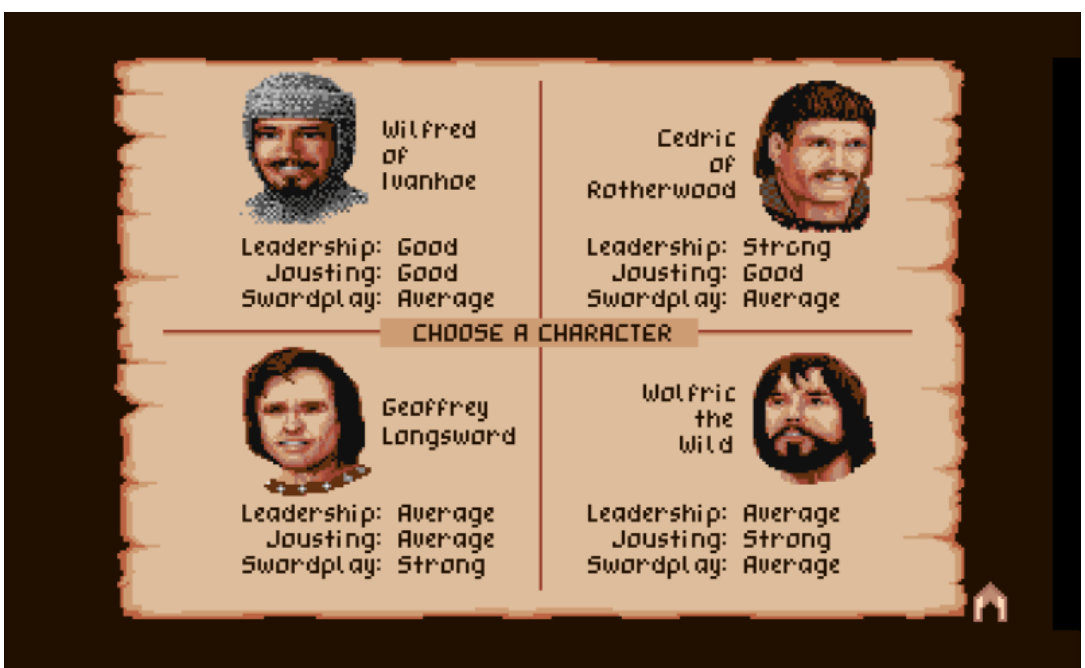

Los cuatro barones sajones con sus características en la versión para Commodore Amiga. Fuente: Mobygames, (Disponible en: <https://www.mobygames.com/game/amiga/defender-of-thecrown/screenshots/gameShotld,31442/>. Consulta: 05 sept. 2019).

Si observamos la portada, vemos una escena dura de batalla entre dos caballeros montados a caballo. El caballero de la izquierda sostiene en uno de sus brazos a una doncella mientras que con la otra alza una alabarda a su enemigo. Por la posición de la mujer y la disposición del mismo, éste encarnaría a un guerrero normando que, según se nos cuenta a lo largo del juego, secuestran a doncellas sajonas y siembran el caos en todo el territorio. Por eso, en la parte derecha, aparece el caballero sajón a lomos de su caballo y blandiendo una espada en actitud de lucha. Va ataviado con una cota de malla y una túnica que le deja moverse con facilidad en su intento de salvar a la dama. Lo que nos transmite esta carátula es, como en Iron Lord, la idea de valentía en la batalla, de honor. Como en el título anterior, nosotros somos uno de esos caballeros que ha vuelto de las Cruzadas junto al rey y debemos cobrar venganza de su asesinato. Por tanto, no importa poner en peligro la vida si así se consigue hacer el Bien. 


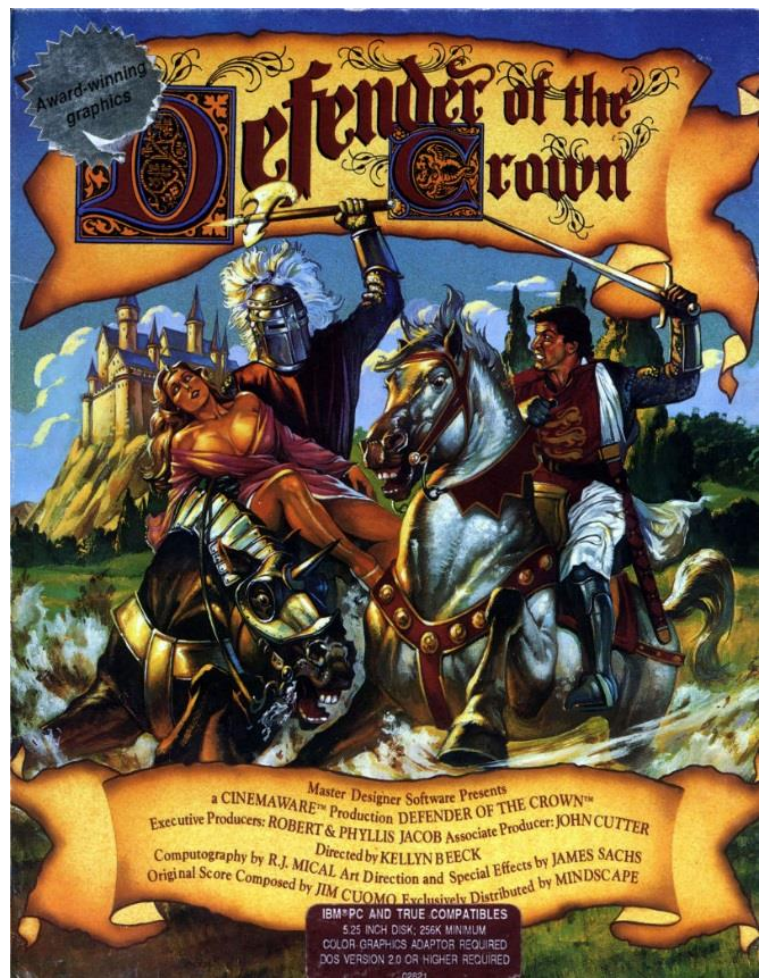

Portada del videojuego Defender of the Crown. Fuente: Mobygames, (Disponible en:

<https://www.mobygames.com/game/c64/iron-lord/cover-art/gameCoverld,157831/>. Consulta: 07 sept. 2019).

El tercero de los títulos seleccionados, Nonamed, está basado en la superación de un campesino joven que quiere llegar a convertirse en caballero, lo que le daría una posición social importante en el reino. Para ello, debe enfrentarse a la prueba anual en el Castillo Sin Nombre, consiguiendo sortear una serie de peligros y salir de allí con vida. Para ello, debe ser valiente y, como veíamos anteriormente, controlar todas las artes de la lucha descritas en un buen caballero medieval. ${ }^{15}$

Al observar la carátula podemos ver que va desprovisto de cualquier tipo de armadura, algo lógico si tenemos en cuenta que se trata de un joven campesino el cual no tiene forma de poder costearse ningún tipo de equipo. Se encuentra escalando una pared del castillo agarrado a una cuerda mientras que es arrastrado hacia abajo por una mujer. La única protección con la que cuenta es con unas botas y unos antebrazos, así como un casco, lo que

\footnotetext{
15 "Los jóvenes aspirantes a Caballeros de su Majestad eran seleccionados en todas las comarcas y villas, de entre aquellos que destacaban en el manejo del arco, la lucha a cuerpo o la espada.". (Nonamed, World of Spectrum. Disponible en: <hhttp://www.worldofspectrum.org/pub/sinclair/games-info/n/Nonamed.txt>. Consulta: 01 ago. 2019.
} 
reflejaba una visión romántica de los ideales del caballero medieval forjada en el honor. ${ }^{16}$ Por tanto, lo que podemos observar es ese concepto actual de lo importante que era la pertenencia a esta clase social en el período medieval.

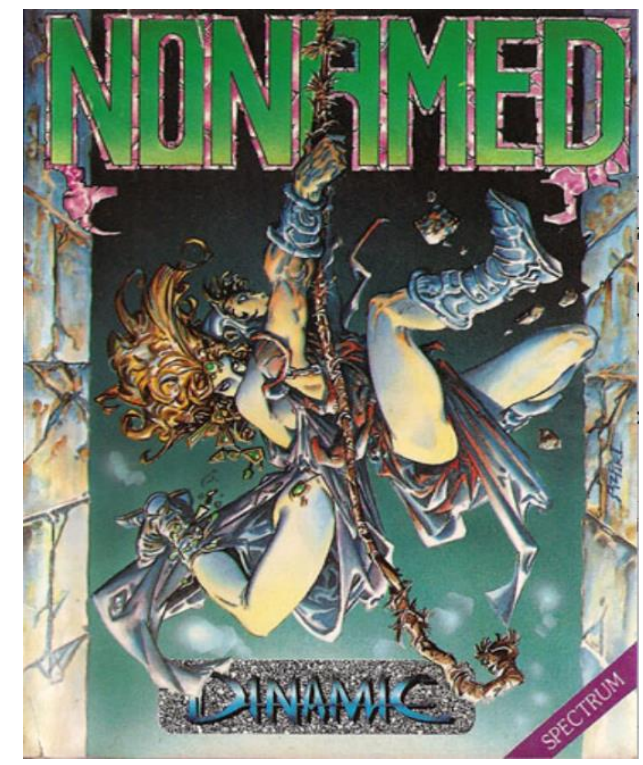

Portada del videojuego Nonamed para Spectrum. Fuente: World of Spectrum, (Disponible en: <http://www.worldofspectrum.org/pub/sinclair/games-inlays/n/Nonamed(MediumCase).jpg>. Consulta 29 ago 2019)

\section{Espacio: El castillo}

Uno de los elementos que más caracterizan a la Edad Media son los castillos. Esta construcción, tan utilizada tanto en películas como en videojuegos, es el símbolo más claro del poder de un territorio en época medieval. Su función principal era la de defender el territorio en el que se encuentra, ya que se erigían una vez conquistada la tierra. ${ }^{17} \mathrm{Al}$ mando de dicha fortaleza se encontraba el señor feudal encargado de proteger la frontera, como podemos ver en el mapa de Defender of the Crown.

\footnotetext{
16 “-: No se te resiste absolutamente nada: aparte de los personajes, has dibujado de todo, desde barcos piratas y diligencias hasta armamento de última generación y naves espaciales ¿todo eso también salía de tu cabeza o te documentabas?

+: Todo era a base de documentación. Cuando me encargaban una portada, se publicaban normalmente a la siguiente semana en la revista Micromanía. Me llamaban y me decían que tenía que estar la portada ya lista, muchas veces sin saber de qué iba el juego (...) Buscaba el efecto impacto en el público. Es lo que he buscado siempre en las portadas."

("Alfonso Azpiri" en Y Yo Vivía sin Conocer Esto. Disponible en: <http://yvysce.com/alfonso-azpiri-ilustradorantes-habia-una-diferencia-artistica-entre-las-portadas-de-videojuegos-ahora-son-todas-iguales/>. Consulta: 02 sept. 2019).

${ }^{17}$ En la Península Ibérica tenemos ejemplos de castillos utilizados como marcas de límites fronterizos entre los reinos cristianos y los árabes, como el Castillo de Berlanga del Duero (s. X), o la fortaleza medieval de Olvera (s. XII).
} 


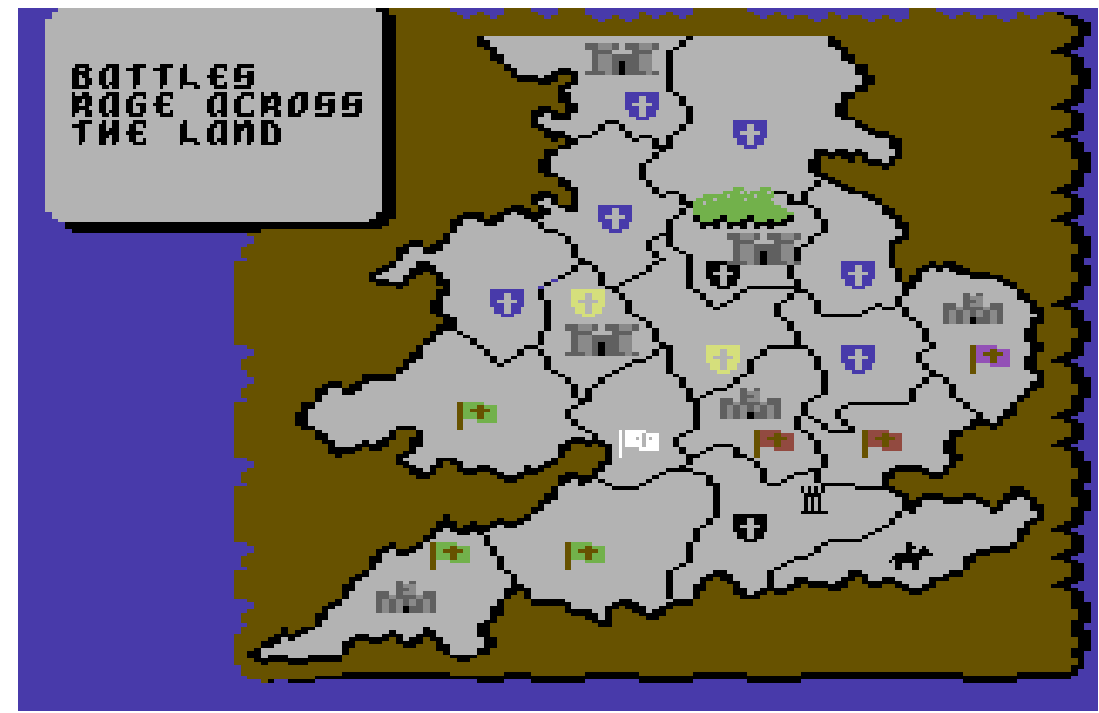

En esta captura de pantalla podemos ver los diferentes castillos que conforman el territorio y sirven como frontera entre los diversos territorios. Defender of the Crown para Commodore 64. Fuente: Mobygames,

(Disponible en: <https://www.mobygames.com/game/c64/defender-of-thecrown/screenshots/gameShotld,828109/>. Consulta: 05 sept. 2019).

Debido a ese carácter defensivo, el castillo ocupa la zona central y más elevada del territorio, creciendo la ciudad en torno al mismo y a partir de ella, las zonas de cultivo. Toda la ciudad solía estar amurallada y rodeada de un foso como medida de precaución para evitar ser sitiados. Así, desde esa fortaleza se podía ver con claridad y antelación cualquier llegada de un ejército aliado o enemigo, lo que hacía posible preparar las defensas y el contraataque.

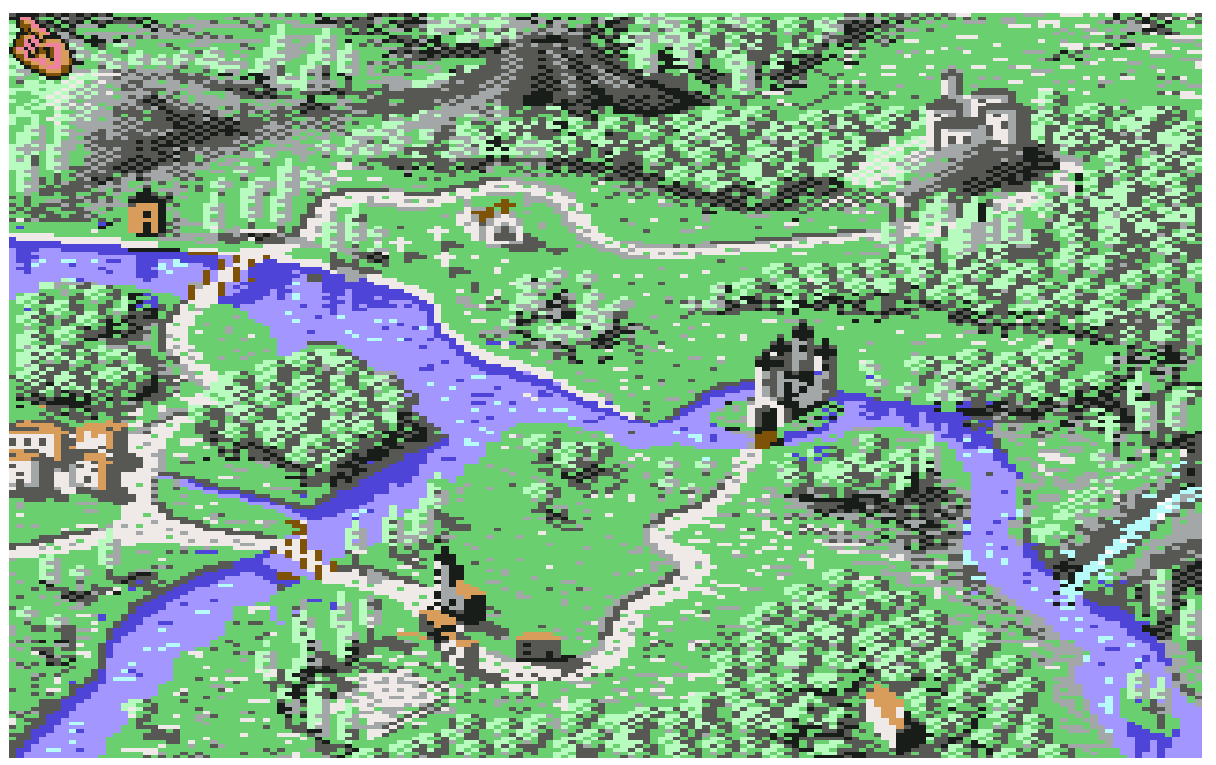

Mapa de dirección de Iron Lord, el cual sirve para dirigir al caballero. Versión para Commodore 64. Fuente: Mobygames (Disponible en: <https://www.mobygames.com/game/c64/ironlord/screenshots/gameShotld,129628/>._Consulta 05 sept. 2019.

Su construcción también buscaba la resistencia a un ataque y por eso estaban construidos en piedra y otros materiales resistentes. Esta factura tenía que resistir no sólo los ataques de guerreros, sino de flechas y catapultas, que eran los métodos de sitio. Por ello, 
contaban con muros altos que lo rodeaban en su totalidad formando dicha muralla, coronados con almenas para vigilar y defender los posibles ataques. Toda la construcción estaba comunicada en el interior de la muralla por un sistema de escaleras y pasadizos que hacía posible la comunicación interna.

Por tanto, la destrucción de un castillo significaba la pérdida simbólica del control de dicha familia en el territorio y el consiguiente vacío de poder. Como consecuencia, provocaba el descrédito e incluso la pobreza de los señores feudales guardianes del mismo.

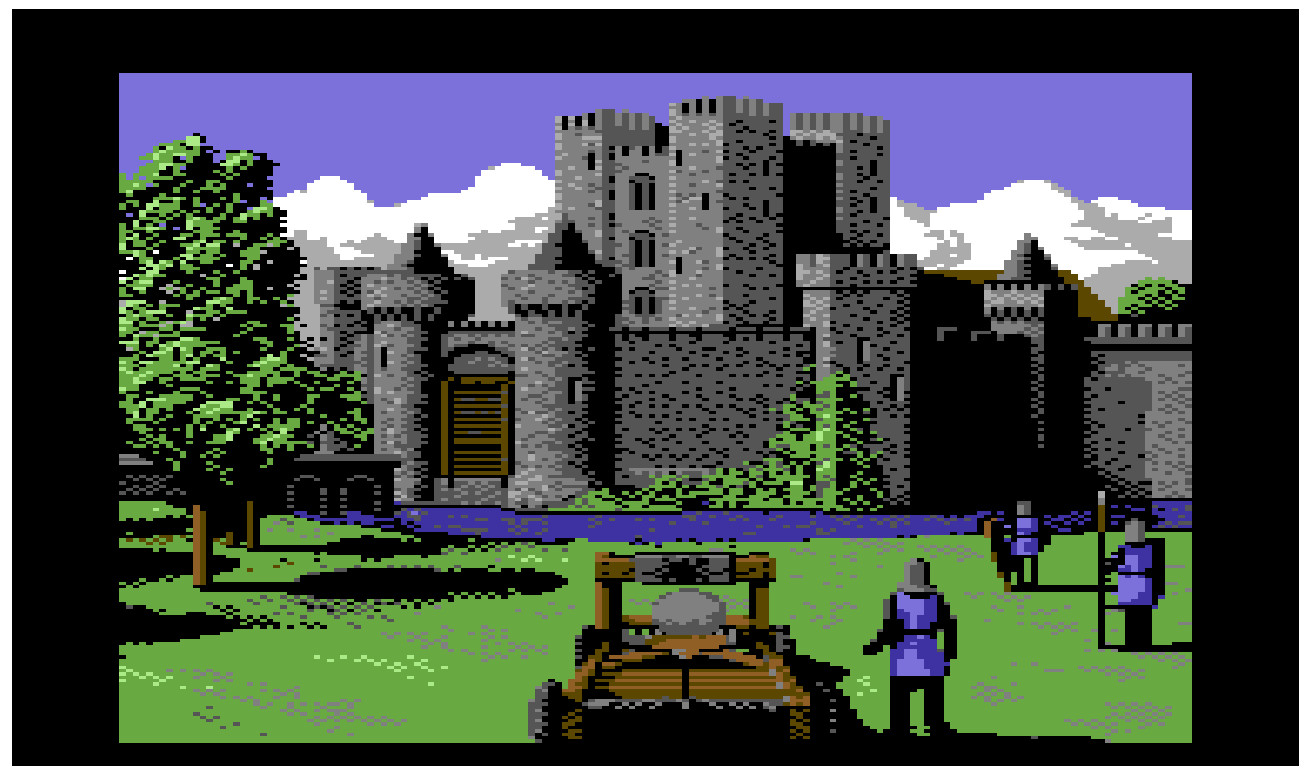

Guerreros atacando un castillo normando en el juego Defender of the Crown. Fuente: Mobygames, (Disponible en: <https://www.mobygames.com/game/c64/defender-of-the-crown/screenshots/gameShotld,126749/>. Consulta: 04 sept. 2019).

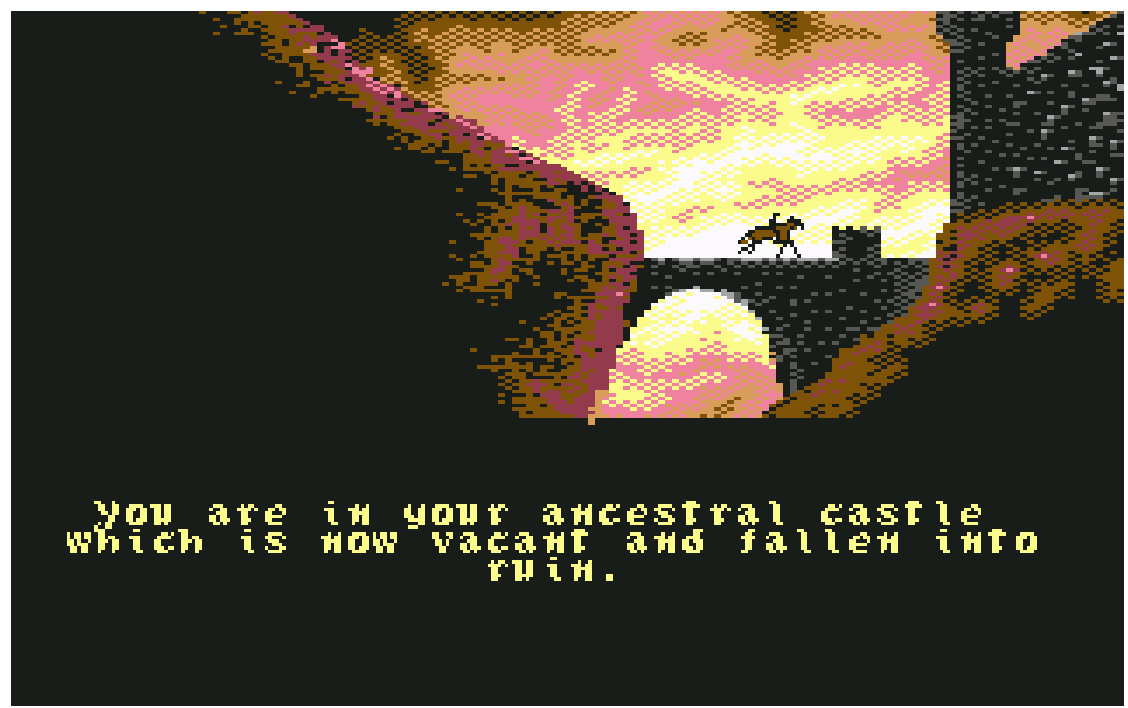

Captura de pantalla de Iron Lord para Commodore 64. Fuente: Mobygames, (Disponible en: <https://www.mobygames.com/game/c64/iron-lord/screenshots/gameShotld,129629/>. Consulta: 05 sept. 2019). 


\section{Peligros}

Hemos descrito brevemente algunos de los elementos que caracterizan el poder en los videojuegos, pero también existe el miedo a perder ese poder. Ese miedo lo conforman tanto los enemigos a los que se debe enfrentar el que lo ostenta como la pérdida en sí de su hegemonía.

La primera causa de la pérdida de poder es, sin duda, la muerte. En los tres videojuegos podemos ver esa representación de una forma más o menos tangible. Tanto en Iron Lord como en Defender of the Crown el devenir del juego es provocado por el asesinato del rey. El primero de ellos comienza con la búsqueda de venganza por parte del sucesor legítimo del reino, ya que la muerte del monarca enlaza con otra forma de peligro como es la usurpación. Hay múltiples historias sobre conspiraciones e intrigas a lo largo de la historia, siendo una de las más conocidas la relativa a Ricardo I de Inglaterra y su hermano el príncipe Juan por la corona de Inglaterra.

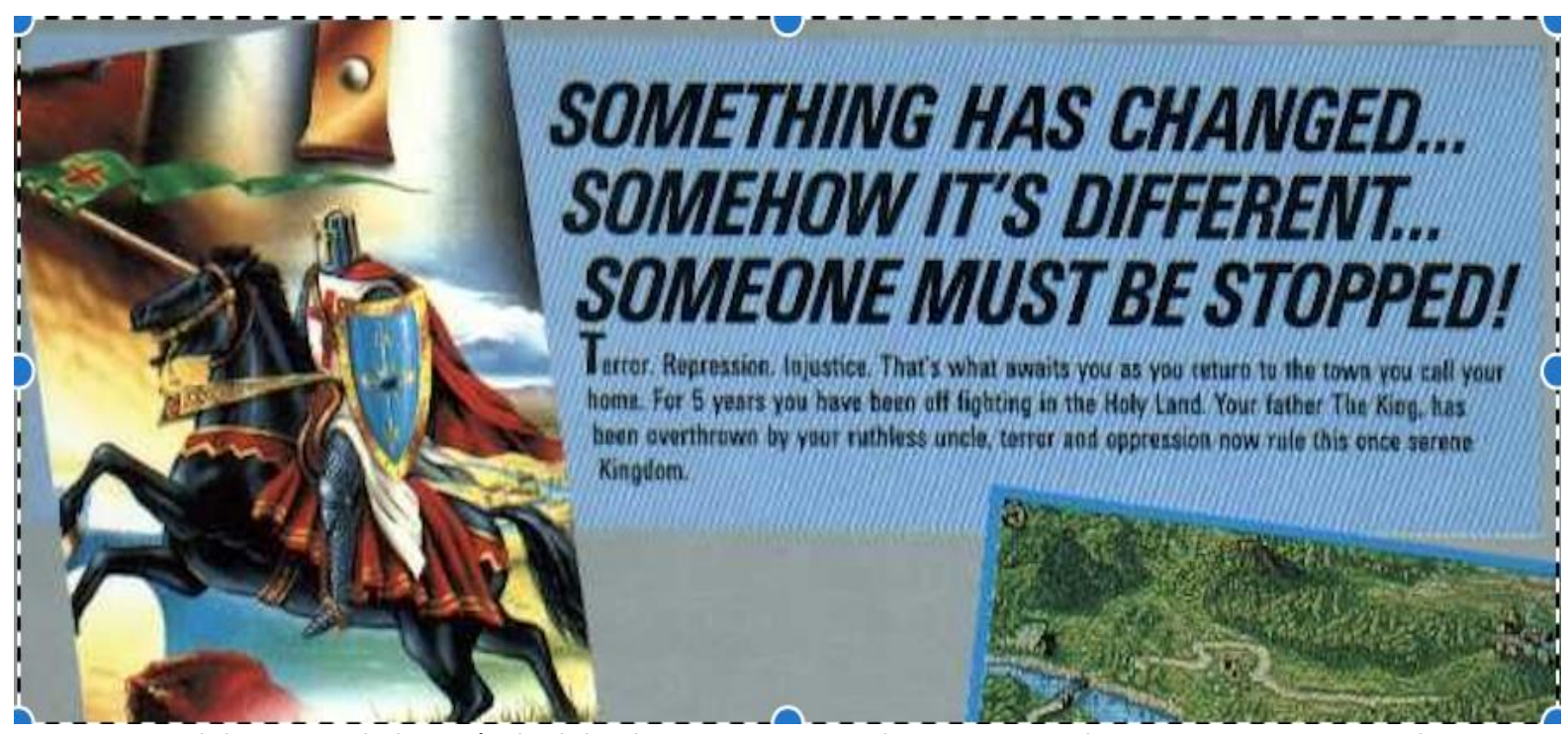

Fragmento del reverso de la carátula del videojuego Iron Lord para Commodore Amiga. Fuente: Mobygames, (Disponible en: <https://www.mobygames.com/game/iron-lord/cover-art/gameCoverld,91695/>. Consulta: 03 sept. 2019).

El asesinato también condiciona el desarrollo del juego en Defender of the Crown. En este título, Robin de Locksley es el encargado de darnos la noticia de la muerte del rey y de la desaparición de la corona del reino. Estos dos hechos desencadenan una verdadera guerra civil entre normandos y sajones por la sucesión. La causa nos la expresa Robin: el asesinato trae consigo un vacío de poder, el cual provoca una situación de inestabilidad en la población. Nada más lejos de la realidad, ya que en la Edad Media hemos comentado que la figura del gobernante era el símbolo de la protección y estabilidad de toda la población. Era coronado 
por la gracia de Dios y bajo este augurio realizaba su mandato proporcionando unidad al reino. Al fenecer dicho personaje es imposible que la paz en el reino dure mucho tiempo, por ello se debe nombrar a un nuevo sucesor cuanto antes.

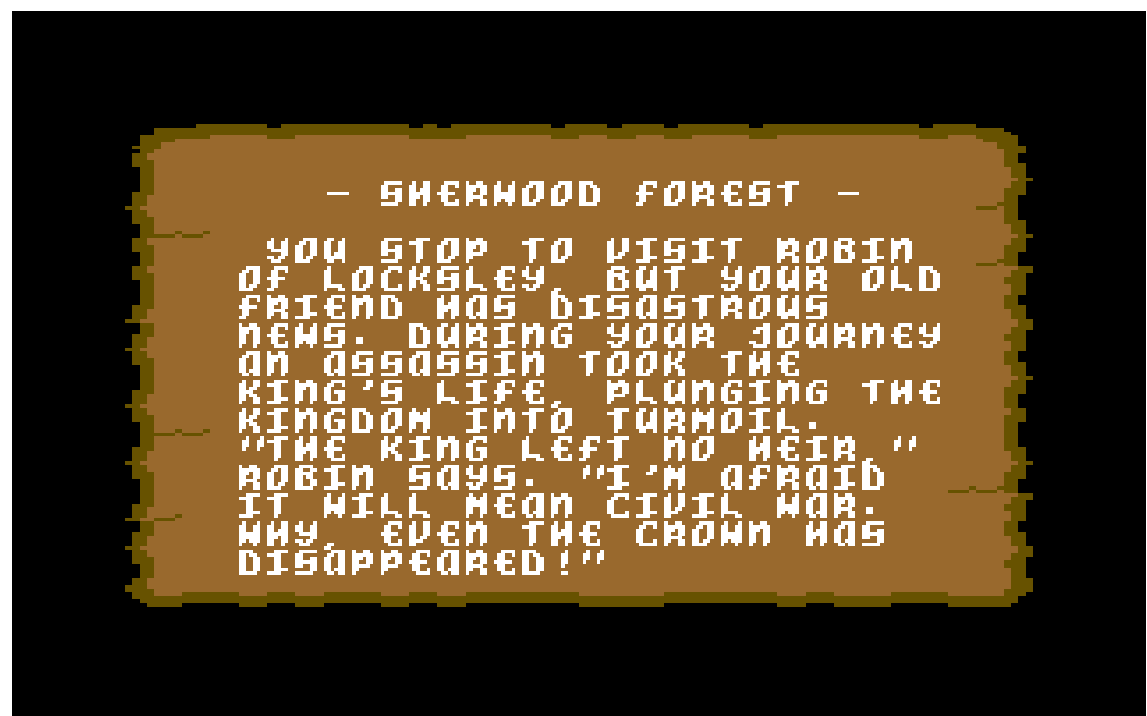

Diálogo entre el protagonista y Robin Hood donde se observa el miedo por el vacío de poder. Defender of the Crown en versión para Commodore 64. Fuente: Mobygames, (Disponible en:

<https://www.mobygames.com/game/c64/defender-of-the-crown/screenshots/gameShotld,828112/>. Consulta: 04 sept. 2019).

Pero la muerte también puede llegar no sólo de una forma física por la acción de una espada o de un arco, sino también por algo más espiritual, la magia. Así es como se nos presenta la acción en Nonamed, donde un castillo se encuentra totalmente hechizado por la acción del hechicero Nilrem. En él, todos los aspirantes que no han conseguido terminar la prueba tienen el aspecto de diversas criaturas monstruosas que atacan al joven aspirante a caballero. Así, podemos ver lanzas y barriles que son lanzados desde diferentes ángulos, así como esqueletos y figuras animalescas que le persiguen en las diversas pantallas. Además, en la parte posterior de la pantalla de juego podemos observar cómo aparece un dragón atacando al hechicero. Las figuras tanto del mago como del dragón son conceptos que se usan con bastante frecuencia para ambientar una película o un videojuego en la Edad Media. Estos elementos son inherentes a dicho periodo ya que la mentalidad medieval era compleja. Mientras que en la actualidad el ser humano distingue entre lo real y lo imaginario, el pensamiento medieval no tenía esa clara distinción. Como consecuencia, se creaba una realidad que aunaba diversas figuras que se consideraban con poder, en este caso mágico. 
Personajes que incluso podían tener poderes curativos o provocar hechizos que podían llegar a causar una maldición en una persona o en un reino. ${ }^{18}$

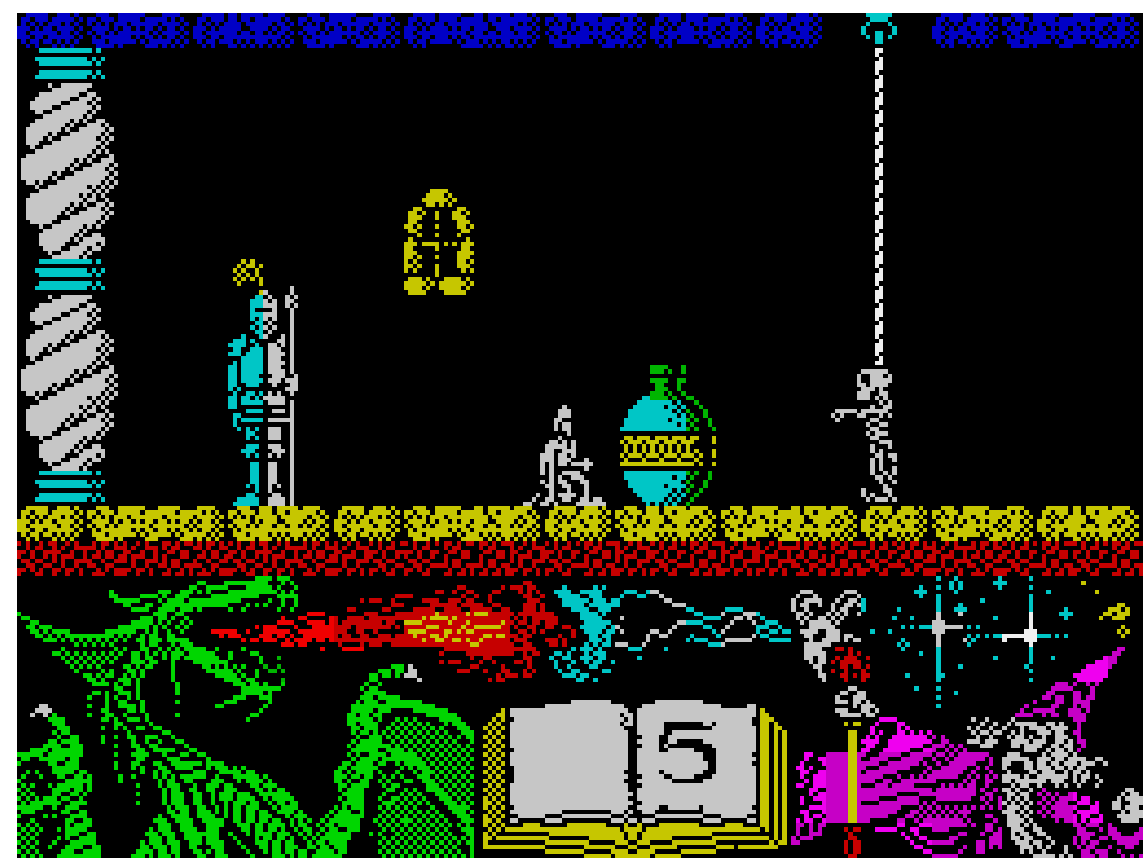

Pantalla de Nonamed en versión para ZX Spectrum. Fuente: Mobygames, (Disponible en: <https://www.mobygames.com/game/zx-spectrum/nonamed/screenshots/gameShotld,153927/>. Consulta: 05 sept. 2019).

\subsection{Los conceptos de representación}

Una vez comentados los elementos que representan el poder en los tres títulos escogidos, debemos presentar todos aquellos conceptos que entroncan con dicha enumeración. Para ello, en un primer punto hablaremos brevemente de los argumentos de los tres videojuegos para así poder comprender su ambientación y su representación. A partir del argumento y del devenir de sus acciones, podemos llevar a cabo una narración de las relaciones de poder que se observan en ellos.

\section{El argumento de los juegos}

Para poder entender las relaciones de poder entre los diversos estamentos sociales, hay que conocer el argumento de los videojuegos. Dicha información sirve, como en las películas, para ambientar la acción así como para crear una serie de representaciones que suelen repetirse en todos los títulos. Así, varios elementos se van repitiendo en los títulos escogidos y conforman una serie de puntos a tener en cuenta.

\footnotetext{
${ }^{18}$ Por eso es interesante que los autores escogiesen el nombre de Nilrem para el hechicero, que no es más que el nombre de Merlín al revés, ya que es una de las figuras más importantes y conocidas del mito artúrico. Desde los relatos artúricos fue considerado un hombre con poderes mágicos, un druida.
} 
El videojuego Defender of the Crown trata sobre el conflicto entre sajones y normandos en la Inglaterra del siglo XII. En 1149 el rey sajón vuelve a su hogar tras haber luchado en las Cruzadas junto a los mejores caballeros sajones del reino. Éste es asesinado y su corona desaparece, lo que provoca un momento de máxima tensión entre sajones y normandos por conseguir el poder de los diversos territorios que componen el reino. El objetivo del juego es conseguir colonizar las diversas zonas en las que se divide Inglaterra controladas tanto por barones sajones como normandos, para así llegar a ser rey.

El argumento de Nonamed se basa en que el rey de una aldea de la Baja Sajonia, Abdul Joneickam Gargoy, celebra anualmente una ceremonia para nombrar a los Caballeros de su Majestad. Para conseguir ser caballero, todos los jóvenes deben pasar una serie de pruebas que concluyen en la prueba final en el Castillo sin Nombre. El protagonista debe recorrer la fortaleza y sobrevivir mientras busca la salida. Para ello, debe esquivar a los anteriores aspirantes que no lo consiguieron, los cuales han sido hechizados y convertidos en ogros y esqueletos. Si consigue salir con vida del castillo, podrá ser armado caballero además de haber sobrevivido a dicha prueba final.

Iron Lord trata sobre una venganza. El rey ha sido asesinado por su hermano, usurpando y haciéndose con el trono. Después de cinco años luchando en las Cruzadas, el caballero templario e hijo del anterior monarca ha regresado y ha conocido la noticia del asesinato. Para cumplir su venganza, necesita reunir un ejército para así enfrentarse a las tropas de su tío, así como luchar contra los diferentes asesinos mandados por él. Una vez combatan las dos armadas, el protagonista deberá perseguir a su enemigo por un laberinto, en el cual se enfrentará a una gran multitud de seres monstruosos hasta conseguir acabar con él.

\section{Relaciones sociales entre el Rey y los caballeros}

El desarrollo de las diversas relaciones sociales son importantes en el videojuego ya que hacen posible el discurrir de la historia y la aventura. Pero también puede ser objeto de estudio como visión del poder entre los diversos estamentos. Podemos observar una serie de relaciones complejas y diversas entre el Rey y los caballeros, pero también entre éstos y sus iguales, así como con las clases populares. Todo ello ayuda a realizar una representación de un mundo que en muchas ocasiones está transformado por los relatos posteriores. 
Hemos mencionado anteriormente la importancia del rey como protector del reino y defensor de la paz, tarea principal de su cargo y eje de la monarquía teocrática medieval. El rey se encuentra por encima y apartado de la sociedad y conseguir relacionarse con él es todo un privilegio. Así lo podemos ver en Nonamed, en el que se nos explica el honor que significaba ser Caballero de su Majestad como salida a un futuro alejado de lo rural. ${ }^{19}$ Aunque el juego termina antes de que podamos verlo, queda implícito en el argumento que si se consigue salir con vida del castillo podrá ser nombrado Caballero. El concepto de nombramiento tiene gran importancia para explicar el poder que tenía el monarca dentro de su reino, ya que era el único que podía llevarlo a cabo por la gracia de Dios. ${ }^{20}$

Pero también existe, como hemos visto, la versión negativa del gobernante, el tirano, descrito en Iron Lord. Si bien dicha caracterización es una mera excusa para desarrollar la venganza del protagonista, nos enseña el lado negativo de dicha concepción política. Si bien el monarca debe procurar la paz en su reino, podía existir alguno que sólo buscase su propio beneficio y llevase a cabo un mal gobierno. Debido precisamente a esa gracia dada por Dios y no por el pueblo, éste último estaba indefenso de los ataques perpetrados por el monarca. No existía en las monarquías cristianas medievales forma alguna de que el pueblo pudiese limitar al rey de ninguna forma, ya que estaba por encima de la ley. ${ }^{21}$ Si nos centramos en la relación con el protagonista, es de venganza por la muerte de su padre, pero también de lucha contra el Mal para así conseguir ser el protector de su pueblo. Para ello, debe reclutar a la mayor cantidad de habitantes del reino para poder levantarse contra el malvado tirano.

Es interesante que el protagonista sea un caballero templario, ya que las Cruzadas nacieron y se desarrollaron encuadradas en la lucha de poder entre Iglesia y emperador cristiano. El siglo XI, que fue el inicio de estas contiendas, fue una época de fricción entre el poder espiritual y el terrenal, una constante búsqueda del control de la sociedad. El culmen fue el año 1095, cuando el papa Urbano II decidió arengar a toda la Cristiandad en la lucha contra los infieles de Oriente para evitar más conflictos en Occidente. El resultado fue el

\footnotetext{
19 "Érase que se era una época pasada donde los hombres para demostrar su valor y conseguir ser nombrados Caballeros del rey, debían someterse a las más duras pruebas." (Nonamed).

${ }^{20}$ Walter Ullmann habla sobre la concepción descendente del poder, en la que el poder del rey viene dado "desde arriba", como representante de Dios en contraposición con la teoría ascendente, la elección del monarca por el pueblo (ULLMANN, 1983, p.124).

${ }^{21}$ Concepto conocido como Munt habla de esa indefensión del pueblo, el cual era un menor de edad que no podía tomar sus propias decisiones y, por tanto, debía ser protegido por el rey (ULLMANN, 1983. p. 55).
} 
control de toda la Cristiandad, incluidos varios monarcas que se aventuraron a luchar en ellas como Ricardo I de Inglaterra o Felipe Augusto de Francia. ${ }^{22}$ Fue así como se crearon las primeras órdenes militares como los Templarios, caballeros con la finalidad de hacer posible la llegada de monjes y hombres para defender las fronteras cristianas a cambio de encomiendas en forma de tierras y rentas. ${ }^{23}$

La idea argumental que podemos ver en Iron Lord también entronca con la de Defender of the Crown. Los hechos que ocurren en este videojuego son contemporáneos de la Tercera Cruzada, en tiempos de Ricardo I “Corazón de León”. En la Inglaterra del siglo XII no sólo existe el poder teocrático del rey así como el poder hierocrático de la Iglesia, sino que se suma una nueva forma de relación y poder, el feudalismo. En el juego, el objetivo es conseguir un ejército y luchar con el resto de barones para conseguir el trono sajón mediante la acumulación de tierras, castillos y territorios. Se nos cuenta que el Rey regresa de las Cruzadas junto a seis de sus barones, los cuales regresan a sus tierras. Por tanto, aunque el rey es considerado superior en la sociedad, es uno más de los grandes señores feudales que completan el territorio sajón. De hecho, viendo el mapa del juego podemos observar que su reino no es más que una amalgama de diferentes territorios más o menos extensos al frente de los cuales está un barón. Por tanto, las relaciones entre barones y el monarca son de igual a igual, encuadrado en las relaciones de vasallaje ${ }^{24}$ y fidelidad de la época. Aunque la acción es posterior a su muerte, el objetivo último es conseguir las mejores relaciones y posibilidades dentro de un círculo de iguales para así ser el primus inter pares.

\section{Concepción del enemigo}

Uno de los elementos más importantes en los videojuegos es la confrontación del protagonista con un enemigo, el cual puede aparecer de forma directa o indirecta. Sean cuales fueren las características del antagonista, siempre es la encarnación de una serie de valores negativos en contraposición con los positivos que describen al protagonista. Esta distinta representación del poder ayuda en el desarrollo de la trama y hace posible marcar un objetivo

\footnotetext{
${ }^{22} \mathrm{Si}$ en un primer momento las Cruzadas contaron con una gran masa popular, a partir de la Tercera Cruzada acudieron señores feudales y reyes.

${ }^{23}$ A partir de la bula Omne datum optimun del papa Eugenio III en 1139, dicha Orden queda estrechamente ligada a la autoridad papal.

${ }^{24}$ Por tanto existen dos partes que se encuentran a la misma altura y cualquiera de ellas puede rescindir dicho contrato (ULLMANN, 1983, p.140-141).
} 
en el juego. Por ello, en este último apéndice del artículo hablaremos de cómo se concibe la figura del otro.

El enemigo puede aparecer de forma diversa, tratándose de un personaje individual o de un colectivo. Así, mientras en Iron Lord el enemigo principal es el rey tirano, tanto en Defender of the Crown como en Nonamed se trata de un grupo - los normandos en el primero, las criaturas encantadas en el segundo. Todos ellos están relacionados con adjetivos de connotación negativa que provocan la antipatía de los jugadores. De igual forma, esta descripción condiciona la visión del mismo y, de forma inconsciente, el posicionamiento entre un personaje y otro, creando una relación entre lo correcto y lo que no lo es. Así, el pueblo normando se describe en Defender of the Crown ${ }^{25}$ como bárbaro y violento; mientras que en Nonamed ${ }^{26}$ las criaturas están malditas por un hechizo del mago Nilrem; como maldito está el rey de Iron Lord, el cual es considerado un tirano.

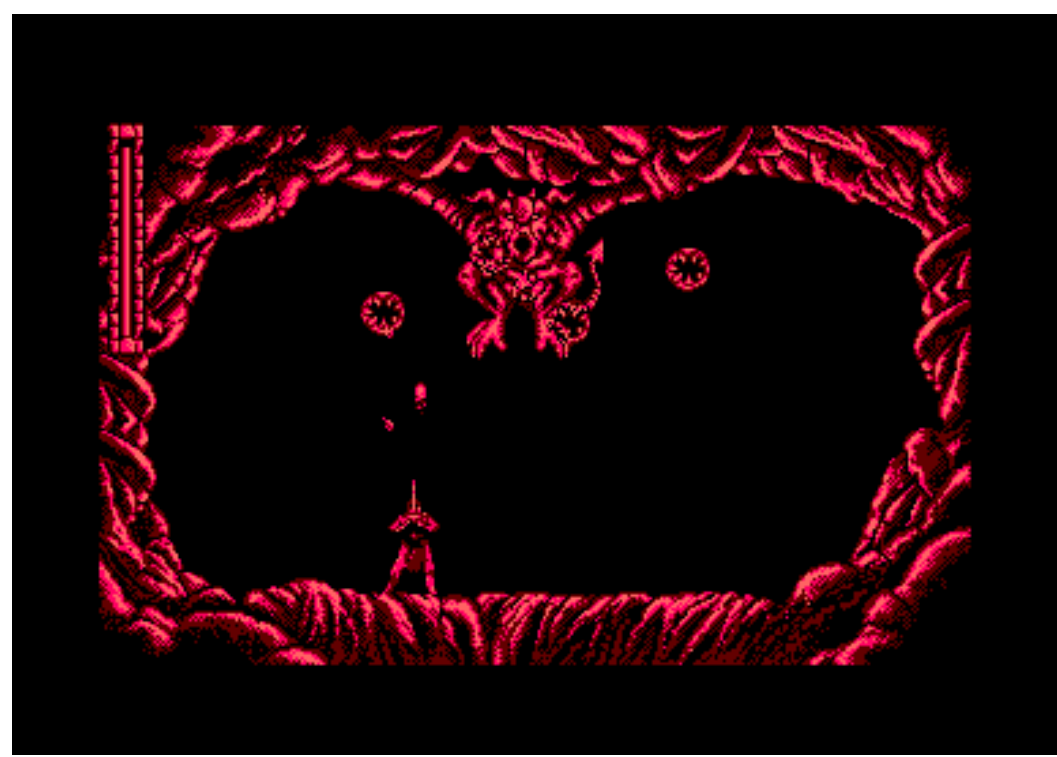

Captura de pantalla de Iron Lord en el momento en el que el caballero lucha contra los demonios. Fuente: $C P C$ Power, (Disponible en: <https://www.cpc-power.com/index.php?page=detail\&num=1178>. Consulta en: 06 sept. 2019).

El enemigo es considerado la alteridad, el otro en sentido peyorativo, la figura que es diferente del personaje protagonista. Esto provoca que en los videojuegos no se tenga en

\footnotetext{
25 "King Richard has been murdered and England thrown into civil war! Amidst the ringing clash of steel and the thunder of charging steeds the bold Saxon knights have chosen you to lead them into battle against the hated Normans". Mensaje publicitario de Defender of the Crown. (Defender of the Crown, Atariamania. Disponible en: $<$ http://www.atarimania.com/game-atari-st-defender-of-the-crown_s7935.html>. Consulta: 07 sept. 2019).

26 "Lo que ocurre es que el castillo se encuentra infectado de los antiguos aspirantes, los cuales, por los efectos de los poderes mágicos del mago Milrem, han sido convertidos en ogros o tétricos esqueletos". (Nonamed, MicroHobby, n. 110, 16).
} 
cuenta la relación que todo guarda dentro de la sociedad medieval, en la que lo real y lo imaginario se entrelazan; donde el conquistador a la vez es conquistado. El adversario siempre encarna otra forma de poder, muchas veces equiparable con la del propio protagonista y, a veces, incluso mayor. Dicho poder puede estar caracterizado tanto por el control de un ejército o de un territorio - Defender of the Crown, Iron Lord-, como por el uso de la fuerza y la magia-Nonamed. Todos estos enemigos se caracterizan porque son el peligro que amenaza con destruir la paz del reino, la cual puede provocar el caos social. Para conseguir frenar la posible inestabilidad del reino, el juego debe contar con el personaje más valiente y aguerrido que existe, quien desarrolla toda la acción del juego.

\section{Conclusiones}

A partir del análisis de los diversos elementos que conforman la representación del poder en los videojuegos de los años 80 , surgen una serie de conclusiones inherentes al tema expuesto en este artículo. La primera de ellas es precisamente la importancia que tiene para los desarrolladores, programadores y diseñadores gráficos el telón de fondo de las historias que se desarrollan. Aunque en muchas ocasiones el argumento sólo sirva como excusa para poder realizar un videojuego, la acción contada crea una atmósfera de credibilidad de la historia que se quiere describir. Pero también tiene un condicionante como es la posible veracidad de los hechos que en los mismos se cuentan. Los tres títulos escogidos se basan en la cultura cinematográfica hollywoodiense y no en fuentes históricas fiables. Por tanto, la representación que se nos presenta en cada uno de ellos viene marcada por una visión distorsionada del período histórico medieval.

Esta reflexión es importante y se debe tener en cuenta siempre que se estudien fuentes actuales que traten hechos históricos pasados. En este caso, la continua utilización de la Edad Media como elemento vertebrador de videojuegos y cine, provoca que el consumidor acepte una serie de elementos y roles como propios de la época. Esta concepción es la causa del desarrollo de un período medieval ajeno al ocurrido, basado en la unión de conceptos propiamente medievales con otros que proceden de épocas modernas, conocida como neomedievalismo. En última instancia genera un desconocimiento de la época misma para el consumidor medio y produce una desinformación o, lo que puede ser peor, una posible manipulación en la narración de la Historia de los pueblos. 
Precisamente por las fuentes en las que se basan dichos juegos, siempre se repite una visión enfocada en la Europa cristiana de la Edad Media. Debido a ello, se repiten una serie de elementos que se confunden entre la cultura popular actual y la cultura medieval. Los ogros, esqueletos y dragones se entrelazan con las narraciones de los valientes caballeros cristianos que luchan por el honor y por rescatar a las damas en apuros. Así, el otro es considerado como inferior al personaje principal de la trama, así como violento y hechizado por la magia - en contraposición clara a la espiritualidad cristiana.

En cuanto a la representación del poder en los videojuegos, prácticamente en todos los títulos se sucede como figura principal el rey. Es considerado el líder político de los diversos reinos; al igual que el líder espiritual es el Papa. Por ello esa doble descripción de los caballeros como caballeros - por tanto al servicio del monarca porque son armados por éste-, cruzados - deben respeto a la Iglesia en sus luchas contra los infieles. Pero también se representa el rey que, como señor feudal, está inserto en una sociedad estamental y es un peldaño más de la escalera de poder. Es una doble vertiente que llama la atención por su contraposición pero que era posible en los reinos medievales de la época.

Por último, es evidente la fuerza que tienen los videojuegos como medio de comunicación de ideas e ideales de diferentes hechos y personajes de la Historia. Las diversas descripciones, argumentos y acciones de todos ellos crean una imagen en el subconsciente de los jugadores y configuran mundos fantásticos insertos en una época histórica. Son la representación visual de todas esas leyendas del folklore que aúnan lo real y lo imaginario, la plasmación de todas aquellas historias que se han ido transmitiendo desde la época antigua. Por tanto, se pueden considerar como una fuente de estudio no sólo del período en el que se ambientan, sino también de la época en la que se han desarrollado.

\section{REFERENCIAS BIBLIOGRÁFICAS}

BARTON, Matt. Interview: Bob Jacob on the Cinemaware. Gamasutra. Disponible en: $<$ https://www.gamasutra.com/view/news/117527/Interview_Bob_Jacob_On_The_Cinemaware_Era. php>.

BROOMFIELD, Mat. Interview with Jim Sachs. CU Amiga Magazine, n. 47, 1994. p. 44-45.

DEFENDER OF THE CROWN. Atarimania. Disponible en: <http://www.atarimania.com/game-atari-stdefender-of-the-crown_s7935.html>.

DEFENDER OF THE CROWN. Mobygames. Disponible en: $<$ https://www.mobygames.com/game/c64/defender-of-the-crown>. 
ECO, Umberto. Dreaming the Middle Ages. Fakes in fakes. In: ECO, Umberto. Travels in Hyperreality, 1986.

ESTEVE GUTIÉRREZ, Jaume. Ocho Quilates: Una Historia de la Edad de Oro del Software Español (19831986). Star-T Magazine Books, 2012.

ESTRADA, Víctor. Entrevista a Alfonso Azpiri. Y Yo Vivía sin Conocer Esto. Disponible en: $<$ http://yvysce.com/alfonso-azpiri-ilustrador-antes-habia-una-diferencia-artistica-entre-las-portadasde-videojuegos-ahora-son-todas-iguales/>.

IRON LORD. CPC Power. Disponible en: <https://www.cpcpower.com/index.php?page=detail\&num=1178>.

. Mobygames. Disponible en: <https://www.mobygames.com/game/c64/iron-lord>.

World of Spectrum. Disponible

$<$ https://www.worldofspectrum.org/infoseekid.cgi?id=0002543>.

KAUFMAN, Amy S. Medieval Unmoored. En: FUGELSO, Karl. (ed.) Studies in Medievalism XIX: Defining Neomedievalism (s). Cambridge: D. S. Brewer, 2010, p.1-11.

NEOMEDIEVALISM. Medieval Electronic Multimedia Organization (MEMO). Disponible en: $<$ http://medievalelectronicmultimedia.org/?page_id=39>.

NONAMED. Mobygames. Disponible en: <https://www.mobygames.com/game/zxspectrum/nonamed>.

World of Spectrum. Disponible en:

<https://www.worldofspectrum.org/infoseekid.cgi?id=0003454>. . MicroHobby, n. 110, p. 16, 1987.

PAGAROLAS SABATÉ, Laureà. Las Primeras Órdenes Militares: Templarios y Hospitalarios. Codex Aquilarensis: Cuadernos de investigación el Monasterio de Santa maría la Real, n. 12, 1996, p. 31-56.

PATTERSON, Mark. Iron Lord. Commodore User, n. 47, 1987, p. 32-33.

REDRUP, Bob. The Adventure Gamer's Manual. United Kingdom: Sigma Press, 1992.

SELLING, Kim. Fantastics Neomedievalism: The Image of the Middle Ages in Popular Fantasy. En: KETTERER, David (ed.). Flashes of the Fantasy. Selected Essays from The War of the Worlds. Centennial, Nineteenth International Conference on the Fantastic in the Arts. Westport, Conn.: Praeger, 2004, p. 211-219.

ULLMANN, Walter. Principios de gobierno y política en la Edad Media. Madrid: Revista de Occidente, 1971.

Historia del pensamiento político en la Edad Media. Barcelona: Ariel, 1983. 